Article

\title{
How Do Scholars Communicate the 'Temporary Turn' in Urban Studies? A Socio-Semiotic Framework
}

\author{
Robin A. Chang \\ Department of European Planning Cultures, School of Spatial Planning, TU Dortmund, 44137 Dortmund, Germany; \\ E-Mail: robin.chang@tu-dortmund.de
}

Submitted: 31 August 2020 | Accepted: 4 December 2020 | Published: 24 February 2021

\begin{abstract}
Interdisciplinarity broadens urban planning praxis and simultaneously deepens how urban research unfurls. Indeed, this breadth and depth diverges and converges the understanding of current and popular concepts such as temporary use (TU)-also recognized as short-term or temporally undefined use of space. Through a meta-research, or research about research approach employing socio-semiotics and bibliometric analyses for the first time in relation to TU, I clarify the increasing scholarly attention to urban interventions by asking: How are urban scholars communicating the TU discourse? A socio-semiotic framework helps unpack the production of meanings as well as symbols channeled through the scholarly institutionalization of TU. Supporting this, I use bibliometric analyses to explicate the production and reproduction of meaning through keywords and citation networks in research literature. This study illuminates epistemological activities and reflects on directions tied to our understanding and articulation of a potential 'Temporary Turn' in theory and practice.
\end{abstract}

\section{Keywords}

bibliometrics; socio-semiotics; temporary turn; temporary use; urban studies

\section{Issue}

This article is part of the issue "Innovations and Development in Urban Planning Scholarship and Research" edited by Thomas W. Sanchez (Virginia Tech, USA).

(C) 2021 by the author; licensee Cogitatio (Lisbon, Portugal). This article is licensed under a Creative Commons Attribution 4.0 International License (CC BY).

\section{Introduction}

Attention for temporary use (TU) grows and is marked by studies that consistently highlight how TU is leveraged for transformation (Martin, Hincks, \& Deas, 2020). Recently, some outline a 'temporary turn' in urban research as well (Stillwagon \& Ghaziani, 2019, p. 875). Motivated by this prospect, I look to the production of meanings in urban scholarship that steer current research orientations and ask: How are urban scholars communicating the TU discourse? One benefit of this pursuit is that it facilitates the momentary stock-taking of urban research on TU. Another benefit is that this builds on studies uncovering trends for the topic in urban planning literature (Stevens, 2018), policy (Honeck, 2018), and media discourses (Matoga, 2019b). Since the establishment of TU as a topic in scholarship, networked collaborations (Galdini, 2020; Stevens, 2018) or mobile and informal policies (Liu, 2017) continue to promulgate its relevance. This is also reflected by an ascending number of publications counts (see Figure 1) and thus invites better nuanced sensitivity towards the symbols and dynamics between practice and theory that support this trend. To set off on this task, I define TU by drawing on Bishop and William's (2012) identification of uses as well as interventions intended for short or undefined periods of time (see also Galdini, 2020; Kim, 2019; Vallance, Dupuis, Thorns, \& Edwards, 2017).

Change-oriented intentions facilitated through TU evolve and are expressed in scholarship through a breadth of contexts. Since western European policy discourses in the 1990s introduced TU to address economic restructuring, deindustrialization and urban shrinkage (Colomb, 2012), the circumstances for TU have expanded to include creative cultures (Andres \& Golubchikov, 2016), policy innovations (Honeck, 2017), design and activism (Tardiveau \& Mallo, 2014) resilience (Chang, 2018) as well as post-disaster recovery and commons 


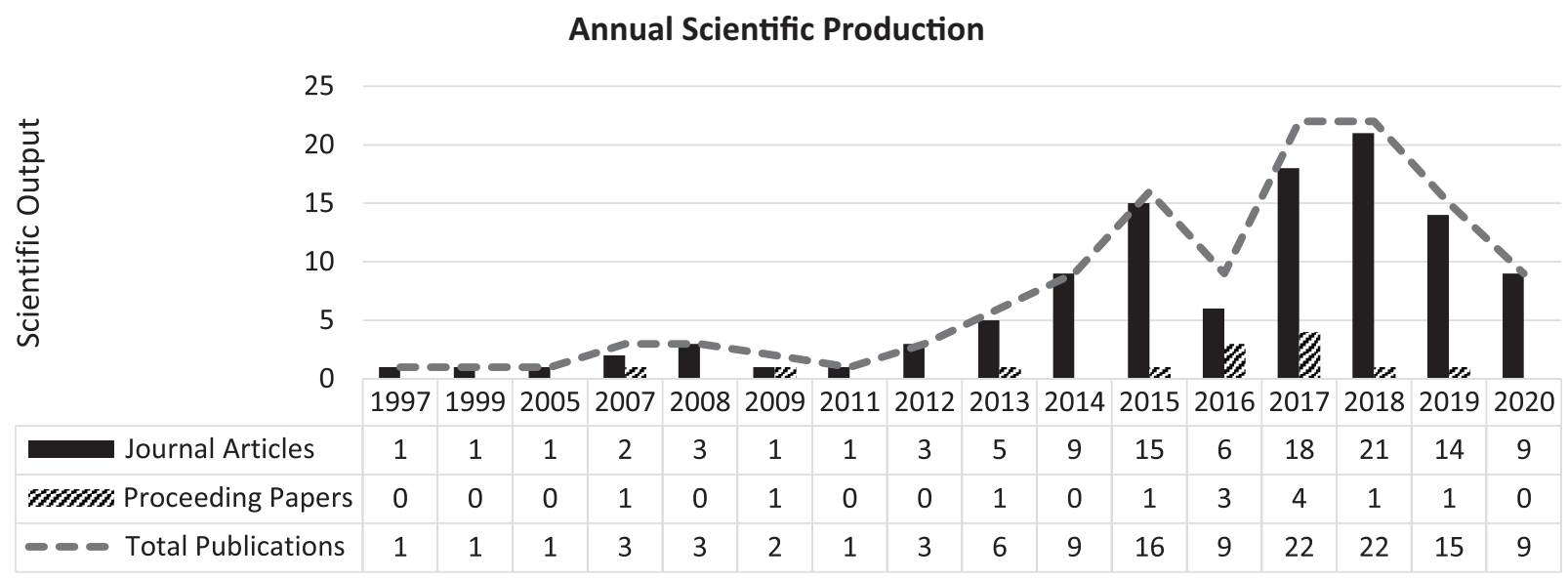

Figure 1. The increase in literature featuring 'temporary use' from 1997 until 2020. This visualizes the climbing number of publications per year containing terms from the search query: ("temporary" OR "interim") AND ("use" OR "urbanism" OR "intervention" OR "design") AND including ("urban" OR "city" OR "town" OR "metrop*" OR "municipal*"). Years without publications are excluded for visual optimization.

(Dombroski, Diprose, \& Boles, 2019). These shifts in praxis and policy position TU on a spectrum that extends from provisional responses in poorly performing cities to instruments leveraging time in neoliberal but also narrowly construed realms (Demailly \& Darly, 2017; LaFrombois, 2017; Wesener, 2018). In parallel, this spectrum is continually propped up by an emerging logomachy of labels for TU; these undermine clarity for those trying to make sense of the topic (Matoga, 2019a). A potential way to reduce confusion and explain the increasingly numerous and variegated accounts for TU is to frame its discourse semiotically as an "articulation of ideology with settlement space" (Gottdiener, 1984 , p. 101). This means that we must recognize how words and ways to articulate scholarship are "linguistic constructs," scaffolding abstract definitions or valueladen explanations for urban phenomena (Ledrut, 1986a, pp. 221-222). These may also help clarify a perspective on a 'Temporary Turn' in urban studies and relevant fields.

Semiotics, or the study of signs provides tools to highlight and explicate how certain symbols result and layer upon each other in the production of meaning (Li, 2017; Ogden \& Richards, 1966). The Semiotic Triangle (Figure 2) delineates the relational production of meaning when a phenomenon (identified as 'referent') is perceived (by a 'signifier') and interpreted (as a 'signified'). These three entities link to form the corners of the Semiotic Triangle; together, they manifest the 'signification process.'

Theorizing in a semiotic manner supports my telos to reflect on how TU transcends from urban streets to studies. More precisely, this is possible by identifying and analyzing the mechanisms and dynamics with which scholarship communicates TU as micro-level "actions

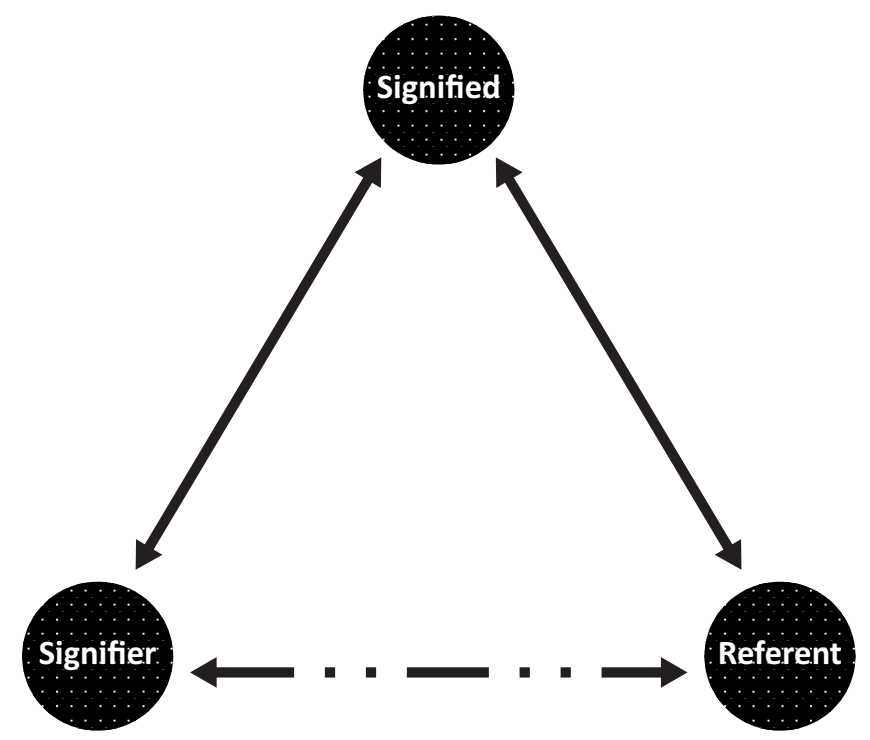

Figure 2. The Semiotic Triangle constituted relationally by the 'referent,' the 'signifier,' and the 'signified.' 
and subjective intentions," to aggregate in "macro-level structures and objective meaning systems" (Li, 2017, pp. 522-523). The following sections undertake this research about research approach and pairs a sociosemiotic framework with bibliometric analyses. Up to date, this is unprecedented in relation to the topic of TU. This adds to few scholarly reviews of TU literature that currently include qualitative content analyses in empirical and policy studies (Stevens, 2018), discourse analyses (Honeck, 2017; Matoga, 2019b) and more common typological reviews of case studies in practice (Bishop \& Williams, 2012; Bragaglia \& Caruso, 2020; Oswalt, Overmeyer, \& Misselwitz, 2013).

\section{Introducing a Socio-Semiotics Framework}

From early on, semioticians drew from language and communication studies to analyze signs. The reason being was to understand their associated meanings and how people, objects and the environment engage in the production of signs along with their representations (Ogden \& Richards, 1966). As such, semiotics helps by recognizing verbal husks, such as keywords, and distinguishing them from their given meanings. We discern this after we see how signifiers interpret spatial referents by engaging in social processes of generating signifieds. This is emphasized visually through the Semiotic Triangle. Signs, united with meanings, affect and establish conceptual and emotional psychologies through relational and social signification processes ( $\mathrm{Li}$, 2017). Urban planning research is no stranger to this as demonstrated by comparable explications of topics such as 'urban practice' through textual analyses (Remm, 2016) or 'place' through linguistic and cognitive analyses (Möystad, 2018).

As a sub-method of semiotics, 'socio-semiotics' provides a tailored means to study signs specific to urbanity. This is because socio-semiotics foregrounds signification processes that relate to cities (Gottdiener \& Lagopoulos, 1986), thus lending itself well to the explication of TU discourses. A socio-semiotic framework builds on urban semiotics by recognizing social interactions (i.e., temporary activities) as well as material objects (i.e., streets or buildings) as vehicles of signification processes; moreover, signification processes are not only social but can be ideological in quality (Gottdiener, 1984). Firstly, socio-semiotics integrates explication through the "scientific analysis of meaning in the urban environment" (Gottdiener, 1984, p. 112). Secondly, this accepts that many groups interpret urban life and generate "multicoded" urban space (Gottdiener, 1986, p. 207). Ideology, in this case, is both context and mechanism in the production of meanings and influences how certain symbols dominate. As a result, the typology of socio-semiotic modes for producing meaning are not only spatial (material or environmental) and social (actor or activity) but also ideological (conceptual or theoretical). Lastly, these are interpreted both through arbitrary "readings" of the environment as well as through analyses of documented discourses (Gottdiener, 1984, p. 113).

\subsection{Semiotic Triangle and Signification Processes}

As introduced, the Semiotic Triangle is the primary tool to deconstruct signs and meaning by positioning together three fundamental mechanisms: the referent, the signifier, and the signified. Researchers operationalize these mechanisms when they perceive urban referents and interpret them selectively as TU signifieds. For instance, I do this when I observe a parking lot that is appropriated by pedestrians and describe it as TU. When referring to signifieds in scholarship, we can find them anchored as keywords. Authors or citation indices suggest or categorize these keywords (Aria, Misuraca, \& Spano, 2020). Changes in keywords also superficially flag the stabilization and fragmentation of scholarly discourses, such as those relating to TU. In practice and reality, keywords may refer directly to referents that we recognize as enacting or interacting objects and phenomena. These often are the source of what a signifier, such as a researcher, communicates (in oral or written formats) to produce a final signified (representation of meanings, ideas, and experiences). Figure 3 illustrates the Semiotic Triangle with respect to TU. Spatial referents are represented in the bottom-right corner and could be temporary interactions between actors or artefacts; examples of these are flexible or modular installations such as appropriated and carpeted parking lots for pedestrian use. These active and social terms extend the inventory of spatial and conventionally passive or material referents such as 'road' or 'tree.' This is also a conceptual stretching of what a referent is and highlights socio-spatial qualities emphasized through socio-semiotics, while enhancing how we articulate spatial development.

In the bottom-left corner of the Semiotic Triangle are signifiers. These are the individuals investigating or engaging with referents. The resulting information they generate or disseminate about temporary phenomenon become coherent as symbolic concepts such as 'TU.' The latter can be identified semiotically as signifieds that sit at the top of the Semiotic Triangle. The linkage through this third and meta-level mechanism to complete the triangle is essential to the production of meaning channeled through signification processes.

Signification processes are not always one-off events. Sometimes, they build off each other through multiple and sequential iterations, during which the mechanisms of the Semiotic Triangle can switch positions. In a first order of signification, referent, signifier and signified relate and generate a denotational sign based on factual or physical perceptions and stimuli (Gottdiener, 1984; Li, 2017). The signs from this process have a "primary function"; these are real and indicative of utility (Eco, 1986, p. 65). For example, we see this through Indonesian civic initiatives converting parking lots into parklets and claiming to engage in TU (Prawata, 2015). 


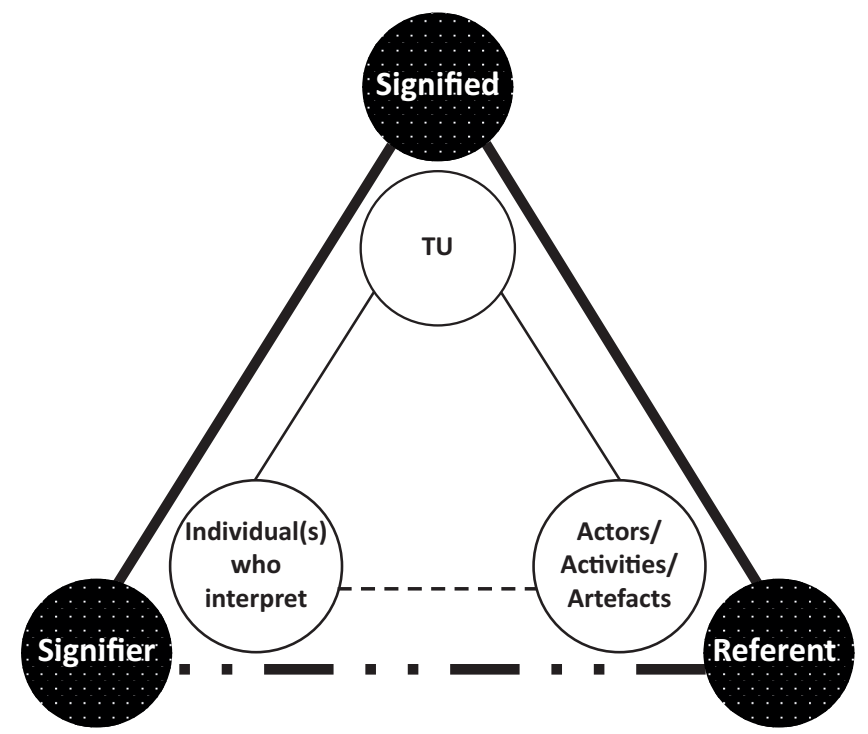

Figure 3. Semiotic Triangle and equivalent TU components.

The chain of signification processes, however, can continue at an abstract and connotative level to generate "secondary function" signs; these drive new, or distort established myths (Li, 2017, p. 526). Signs from second order signification processes represent symbolically and less functionally. In the case study by Prawata (2015), TU is a representation of a second order sign and also expressed as an instance of 'Tactical Urbanism.' The latter is a variant that potentially contests or superimposes itself on the former signified of 'TU.' Parklets in this vignette are no longer just temporary phenomena but place-making interventions that firstly drive TU and secondly contest or distort its myth through
'Tactical Urbanism.' Figure 4 illustrates Prawata's example of these layered orders of the signification process.

\subsection{Institutionalizing Myths through Transfunctionalization}

Both levels of signification involve the social production of meanings and engage different social groups. Returning to the parklet illustration, the first order of signification involves citizens and designer activists as signifiers. Whereas, the second order process involves a different social group including the author and other scholars who advance 'Tactical Urbanism' as an alterna-

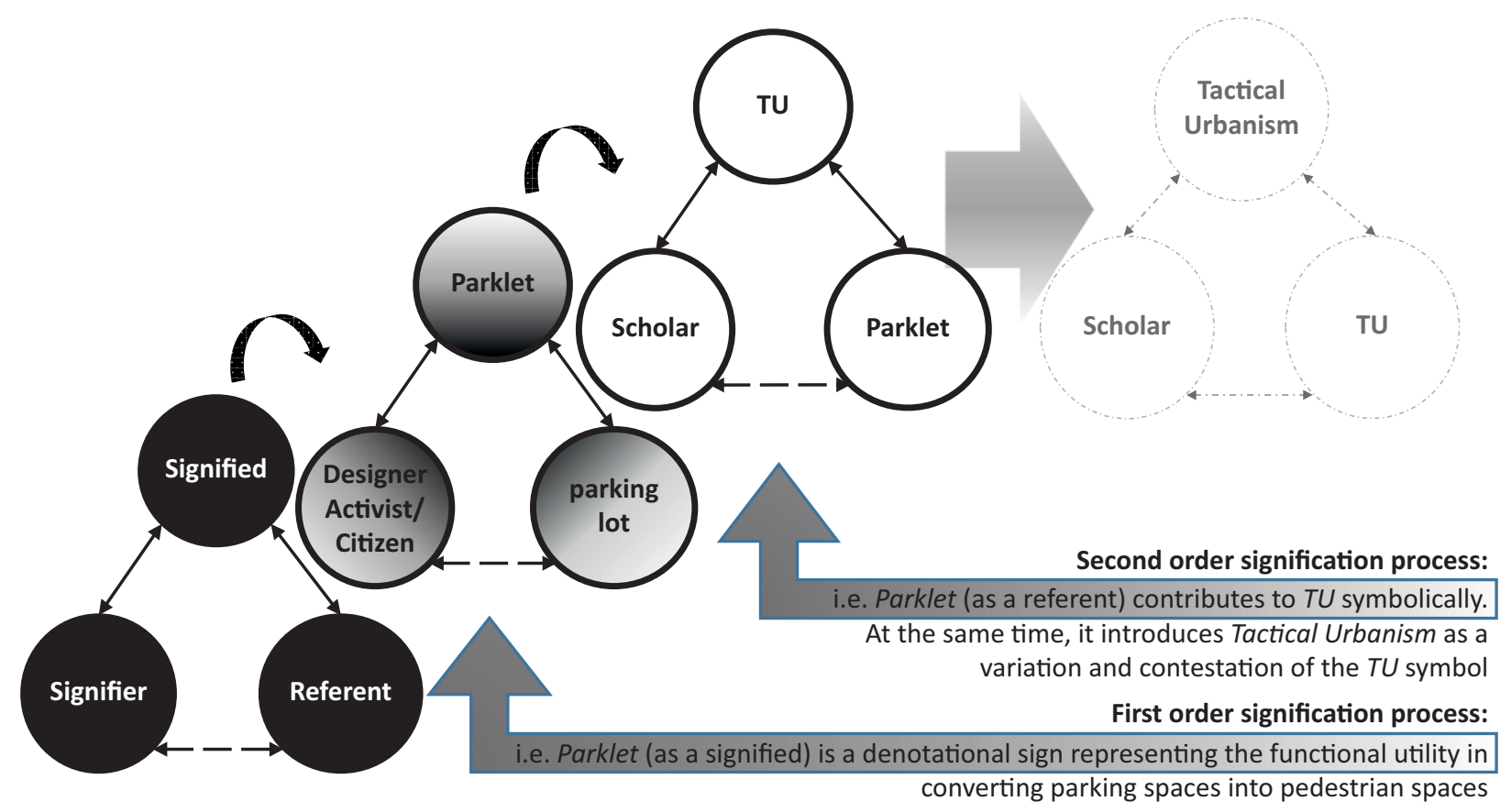

Figure 4. Illustration of the first and second order of signification through which 'parklet' as a semiotic mechanism switches positions, and 'tactical urbanism' is introduced as a variant of the 'TU' symbol. 
tive signified. Attending to each iteration of the signification process are diverse perspectives that shape new and multiple meanings. As a result, interpretations abound with signifieds as "mythical creatures, extremely imprecise, and at a certain point [becoming] the signifiers of something else" (Barthes, 1986, p. 94). This characterizes plural or polysemic qualities in symbols such as TU, making them purposeful for many and yet increasingly nebulous for all. Signifiers engaging in the production of meaning can use these polysemic symbols as they see fit by taking advantage of, and contributing to rich overlays of ideological and second order signification processes (Gottdiener, 2011). An interpretation of TU, in this light, is that it metamorphoses unceasingly through a myriad of symbolic keywords. This is a process of abstraction (from a factual to functional symbol) and refraction (from theory to diverse meta-analytical myths) in scholarship. This is also a process of institutionalizing symbolic myths that are not yet coherent at the ground level, unless a symbol is explicitly articulated to create a new signified. For instance, 'TU' might appear in policy publications and thus progress a new symbol under the heading of 'Tactical Urbanism' for urban regeneration. Fortunately, it is possible to tease this out in detailed content analyses or through bibliometric techniques that analyse semiotic relationships. These analytical methods make clear how meanings and symbols aggregate in scholarship and are facilitated by epistemic communities who refract, channel and network their own interpretations (De Bruijn \& Gerrits, 2018).

A socio-semiotic term for second order signification processes is 'transfunctionalization'; through this, "a distinction is made between the [immediate] use of objects and [the] socially sustained use of the object" (Gottdiener, 1985, p. 988; Krampen, 1979). The basis of 'transfunctionalization' is social and ideological. It re-creates meaning sourced from ideologies of diverse epistemic communities. Figure 4 , hints at this for instance, and is confirmed by detailed examination of Prawata's (2015) text, which draws upon the urban design community and scholars to advance TU as 'Tactical Urbanism.' Other parallel socio-semiotic patterns can be drawn between TU and terms including but not limited to 'DIY Urbanism' (Iveson, 2013), 'Insurgent Urbanism' (Groth \& Corijn, 2005) or 'Austerity Urbanism' (Gillespie, Hardy, \& Watt, 2018). These underline how mythical ideas build and layer upon functional facts. Understood this way, TU is just as much about the immediate and functional activities on a vacant site as it is the summation of new TU symbols that now thrust us towards a possible Temporary Turn in scholarship. Spatial and social production of meaning propel and elevate semantic symbols such as 'parklet,' which scholars integrate into the reproduction of existing ideological concepts such as TU, or the generation of new alternatives such as 'Tactical Urbanism.' This also underscores a political economic framing of how a Marxist approach to the production of space (Lefebvre, 1996) and production of knowledge in the Althusserian sense, influence the building environment through symbolic or socio-semiotic processes (Gottdiener, 1984).

\section{Methodology}

In the previous sections, I introduced a socio-semiotic framework to explicate TU as an institutionalizing and polysemic concept. This results from spatial, social and ideological processes. To support this, I use bibliometrics to identify, summarize and visualize trends at a static point in time (Aria \& Cuccurullo, 2017). Bibliometrics is useful for detecting shifts in scholarly discourses and confirming intuitive conclusions about scholarship development and dissemination (Kirby, 2012). The findings from these methods support the suggestion that signifieds embodied in keywords, produce TU while challenging it symbolically with new signifieds. These could reflect how research orientations might attempt to balance and pursue innovative narratives instead of re-enforcing stable accounts (Stillwagon \& Ghaziani, 2019). The pairing of a socio-semiotic framing with bibliometrics to study TU has not been conducted up to date. This extends the range of bibliometric studies on urban topics such as resilience (Meerow, Newell, \& Stults, 2016), participation (Certoma, Corsini, \& Rizzi, 2015) and industrial districts (Hervas-Oliver, Gonzalez, Caja, \& Sempere-Ripoll, 2015). Bibliometrics draws information from three types of indicators: publication count, citations and impact factor, as well as co-citation and co-word analysis. I queried these meta-data information through Web of Science (established by ISI/Thomson) by means of categorical combinations of keywords that 1 ) either explicitly or implicitly refer to momentary temporality, while not adhering to regular, linear nor strategic planning processes; these relate to 2) functionality and form; and are situated within 3) urban areas. The queries consisted of: ("temporary" OR "interim") along with ("use" OR "urbanism" OR "intervention" OR "design") in combination with ("urban" OR "city" OR "town" OR "metrop*" OR "municipal*"). The "*' symbol denotes a word root, which includes all words with the root in the query. I derived an earlier version of this query from initial reviews of publications on TU and finally expanded the query to include more spatial parameters, similar to other systematic reviews or bibliometric studies (De Bruijn \& Gerrits, 2018; Meerow \& Newell, 2015). The search queries employed both 'temporary' and 'interim' as these represent the earliest modifying terms for 'use' in initial publications; they are also direct translations from terminology in pioneering policies and instruments from mostly German-speaking regions of Europe (Havemann \& Schild, 2007; Rall \& Haase, 2011; Stevens, 2018).

I ran an initial query in March 2019 and repeated a second iteration in August 2020 to gauge for changes in output. The second iteration of the query generated 4,842 documents (4,321 documents in first round). From this, 4,568 (4,034 documents in first round) 
English documents remained that I filtered down to 518 (443 documents in first round) documents based off urban planning relevant research categories. Since English serves as the lingua franca for scholarly communities, the query excluded other languages. Eventually, 481 ( 358 documents in first round) documents in the form of articles and proceeding papers remained, of which only 123 (119 documents in first round) were determined manually, as relevant. After reviewing the final corpus of documents (see the Supplementary File), analytical insights generated through bibliometrics helped substantiate my conceptual and socio-semiotic framing. Figure 5 visually breaks down the stepwise approach to the query and filtering strategy.

The key source of information for my findings are authors' keywords and citations; the latter indicate interest and recognition from other fellow scholars as well as the usefulness and qualitative impacts of journals (Archambault \& Gagné, 2004). It is important to note that citations as a proxy of quality favour older publications that have had more time to attract an audience (De Bruijn \& Gerrits, 2018). Co-word and co-citation analyses distinguish research activity through visualizations (Archambault \& Gagné, 2004) and are applicable to publication counts, citations, and impact factors; these illustrate more nuanced relations within and between research fields by identifying and mapping key or influential authors (Archambault \& Gagné, 2004). I make use of both co-citation and co-word analyses to illustrate influential authors as well as subject-relatedness and clustering of co-occurring terms in keywords, abstracts or full texts. Cluster or semantic maps help draw or confirm conclusions on emergent themes in research fields and visualize relationships through patterns of centrality and density (Aria \& Cuccurullo, 2017; Fu \& Zhang, 2017). For the analysis in this contribution I made use of the tool bibliometrix R-package and the Biblioshiny user interface, which were developed with $\mathrm{R}$ language to support standard bibliometric workflows (Aria \& Cuccurullo, 2017).

\section{Evaluating a Temporary Turn}

The results from the bibliometric analyses confirm an increasing attention to, and variation in conceptualiz-

\section{Literature Query}

\begin{tabular}{l|c}
$\begin{array}{l}\text { The Web of Science (established by ISI/Thomson) } \\
\text { database was queried for categorical combinations } \\
\text { of keywords. These characterized temporary uses } \\
\text { not adhering to regular, linear nor strategic }\end{array}$ & $\begin{array}{c}\text { Search query terms: ((('temporary' OR 'interim') } \\
\text { planning processes in urban areas. }\end{array}$ \\
$\begin{array}{l}\text { plesign') AND ('* urban' OR '*city' OR 'town' OR } \\
\text { 'metrop*' OR 'municipal*'))) }\end{array}$
\end{tabular}

\section{Language Filtering}

Other languages except for English (serves as lingua franca in scholarship) were excluded.
4,568 documents in 2020 (4,034 documents in 2019)

\section{Categorical Filtering}

Documents not included in the Web of Science categories of 'urban studies', 'environmental studies', 'geography',

'architecture,' 'transportation', 'sociology', 'management' or 518 documents in 2020 (443 documents in 2019)

'regional urban planning' were excluded.

\section{Publication Type Filtering}

All publications other than articles and proceeding papers were excluded. These undergo minimum review standards and are often considered accepted by the scholarship community

481 documents in 2020 (358 in 2019) at large.

\section{Manual Content Filtering}

\footnotetext{
All documents not clearly relevant to TU were excluded. A manual process of categorizing the centrality of TU on a scale of 1 to 4 was used to determine the relevancy of the publications. This took into account explicit and implied relationship to TU as well as contextual discussions for TU.
}

Figure 5. Breakdown of the stepwise approach to the literature search and filtering strategy. 
ing TU since 1997. Figure 1 is a first indication of this. Along with publication counts, keyword dynamics can also be analysed through bibliometrics. Figure 6 traces the keyword growth associated with TU from 2007 and on; established keywords may as well serve as signifieds in this context. The analysis is generated through the cumulate occurrences of keywords with loess smoothing. At the surface, the keywords show how TU institutionalized and now contends with new and emerging signifieds. After 2011, new signifieds embodied in 'Temporary Urbanism' and 'Tactical Urbanism' appear. Also, they are increasingly more common than other keywords represented as modified 'urbanisms' (i.e., Austerity Urbanism, DIY Urbanism, etc.). Like TU, the use of 'Temporary Urbanism' and 'Tactical Urbanism' is pronounced according to keyword growth, since they achieved a minimum number of occurrences in order to aggregate enough significance. Notwithstanding, a manual content analysis substantiates that titular keywords such as 'Tactical Urbanism' or 'Temporary Urbanism' often subsume other keyword variants in the publication texts. These include but are not limited to 'grand urbanism' (Kassens-Noor, 2016), 'DIY Urbanism' (Talen, 2015) or 'Pop-up Urbanism' (Harris, 2015). 'Temporary Use' and 'Temporary Uses' are still comparably popular; most likely because they appear consistently in concert with the signifieds 'Temporary Urbanism' and 'Tactical Urbanism' as referent keywords. Only 53 out of the total 123 publications refer explicitly to TU as referents and discuss TU centrally as a signifieds. The remaining 70 publications imply TU through referents such as structures (Del Signore, 2017), interventions (Davis, 2008; Martini
\& Ramaccini, 2016), experiments (Copley, Bowring, \& Abbott, 2015), spaces (McGlone, 2016; Muniandy, 2015) or clusters (Comunian, 2017) that are temporary. What is also inferred are distinct phases in scholarship; each of these frame TU differently. A first phase prior to 2011 discusses TU through denotative or first-order signification processes. Let us recall that these processes result in primary or functional symbols (Eco, 1986). The content analyses of earlier publications corroborate this as they feature typological studies of TU that discuss ranges and types of practices on the ground (Bishop \& Williams, 2012; Groth \& Corijn, 2005; Oswalt et al., 2013; Rall \& Haase, 2011). Accompanying this, 'Temporary Uses' often appears to characterize the diversity of the pragmatic activities; these co-occur commonly with the keywords 'Temporary' and 'Design.' In this phase, initial and conceptual frameworks are presented. These are outcomes from studies that investigate transitions in governance or policy responses towards economic restructuring (Rall \& Haase, 2011), neoliberalization (Groth \& Corijn, 2005), or new forms of citizen engagement (Centner, 2012). Few publications, however, focus on TU through an entirely theoretical lens. Instead, the majority of the publications refer to provisional, diverse and utilitarian practices or methods (Dinzey-Flores, 2007; Havemann \& Schild, 2007; Rian, Chang, Park, \& Ahn, 2008; Schrooten, Coopman, \& Kindt, 2007).

The latter and more recent phase in TU discourse is comparatively abstract with diverging keywords. This could signify the transfunctionalization of TU. There is a visible ascension of 'Temporary Urbanism' and 'Tactical Urbanism,' while the discussion of TU broad-

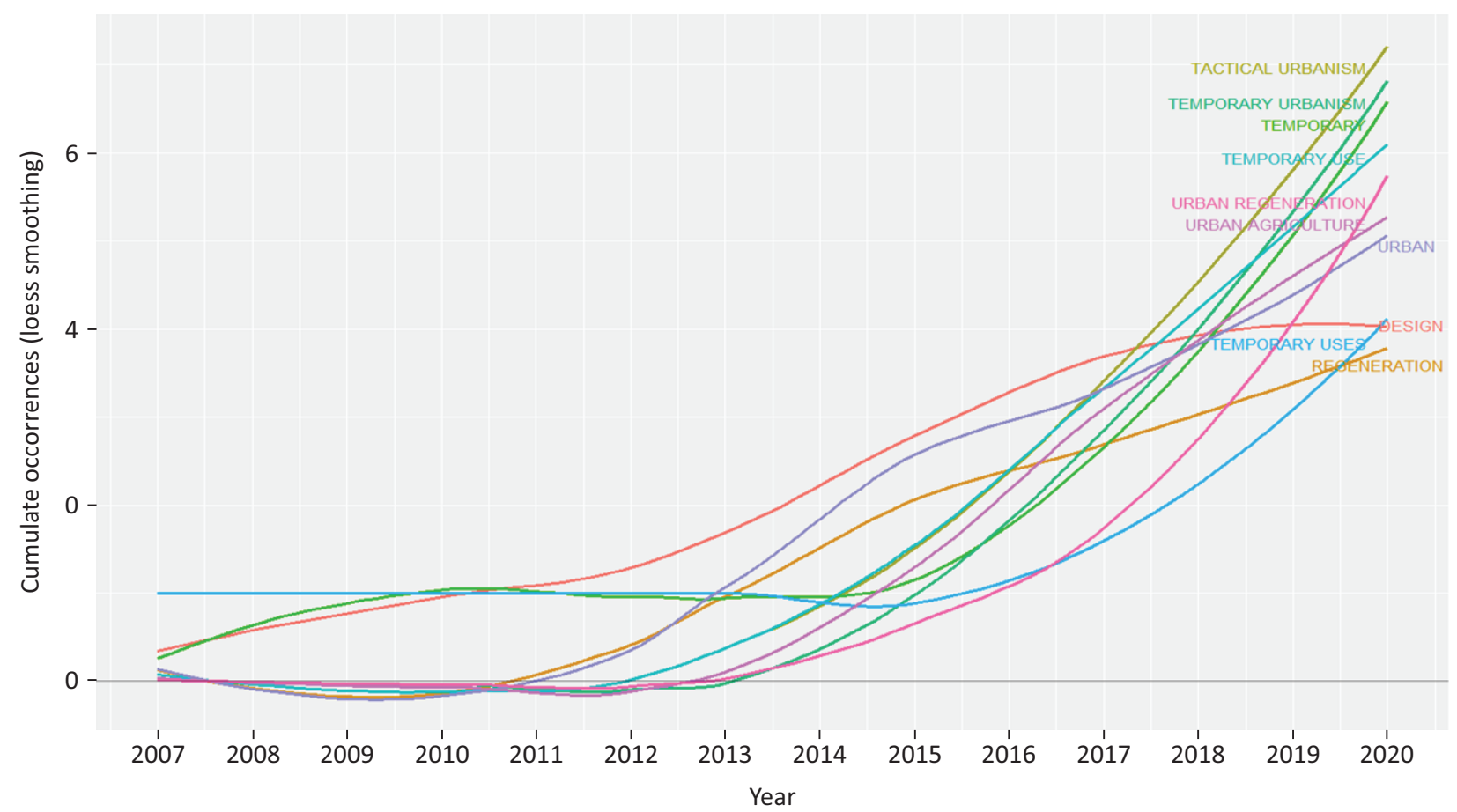

Figure 6. Growth of cumulative occurrences for top signifieds from titles, abstracts, and keywords, featuring topic of TU from 2007 until 2020. 
ens to encompass general processes of urban transformation (Nemeth \& Langhorst, 2014; Szaton, 2018). Put differently, the canvas for TU is expanding. What is notable, however, is the foregrounding of boosterist strategies for place-making (Galdini, 2020; Rota \& Salone, 2014) that is repeated through other modes of action including but not limited to entrepreneurialism (Overdiek, 2018), creative cultures (Andres, 2013), or mega-events (Ferreri, 2019; Kassens-Noor, 2016). More prominently featured are also discussions on access to (Dubeaux \& Cunningham Sabot, 2018) and the financialization of land through TU (O'Callaghan, Di Feliciantonio, $\&$ Byrne, 2018). These confirm or reproduce narratives and show that "urban space is not a simple container of social processes, but the condensation of often contentious group interactions"; these "[involve] signifying practices as much as non-semiotic processes, such as the class struggle at the place of work" (Gottdiener, 1986, p. 214). Political economic undertones sound and connect the production of knowledge through sociosemiotic processes with the built environment. At the same time, a Temporary Turn in urban practice that is catalyzed by socioeconomic pressures also reverberates in urban scholarship. These are reproduced through few, but prevailing TU signifieds that are nuanced with similar political and socioeconomic narratives.

Thematically, we can also discern this by mapping 500 of the most common and co-occurring keywords as illustrated in Figure 7. Distinct cluster bubbles feature the most common keyword in the cluster as the cluster label. Bubble size indicates the proportion of cluster word occurrences, and bubble location is a measure of
Callon centrality and density (Aria et al., 2020). The latter is helpful for revealing themes that are "emerging or declining" (lower-left quadrant), "highly developed and isolated" (upper-left quadrant), "motor themes" (upper-right quadrant), and finally "basic and transversal" or relevant to a specific domain and the diverse research areas within a field (lower-right quadrant; Aria et al., 2020, pp. 821-822).

The most relevant clusters for a socio-semiotic framing of a Temporary Turn are positioned in the quadrants to the right. In the lower-right quadrant, TU represents the biggest cluster and co-occurs most commonly with 43 other keywords. 'Temporary Urbanism' follows suit as the second biggest cluster and co-occurs commonly with 40 other keywords. In comparison, 'Tactical Urbanism' is most weakly represented of the signifieds by co-occurring commonly with 30 other keywords (refer to SM.2 Breakdown of Thematic Map of the 500 Most Common Co-Occurring Keywords and Keyword Clusters in the Supplementary File for the full breakdown). The location of TU signals its fundamental and cross-cutting relevance. This affirms the status of TU as the more established signified within the diverse research areas of urban scholarship. In contrast, 'Temporary Urbanism' and 'Tactical Urbanism' are positioned towards the upper-right quadrant of the thematic map. Their locations indicate a high degree of development and importance for urban studies. In comparison to 'Temporary Use' however, there is not as high of a degree of interdisciplinary relevance for all urban research fields. A finer sweep of the co-occurring keywords show that ideologically or critically nuanced terms such as, but not limited

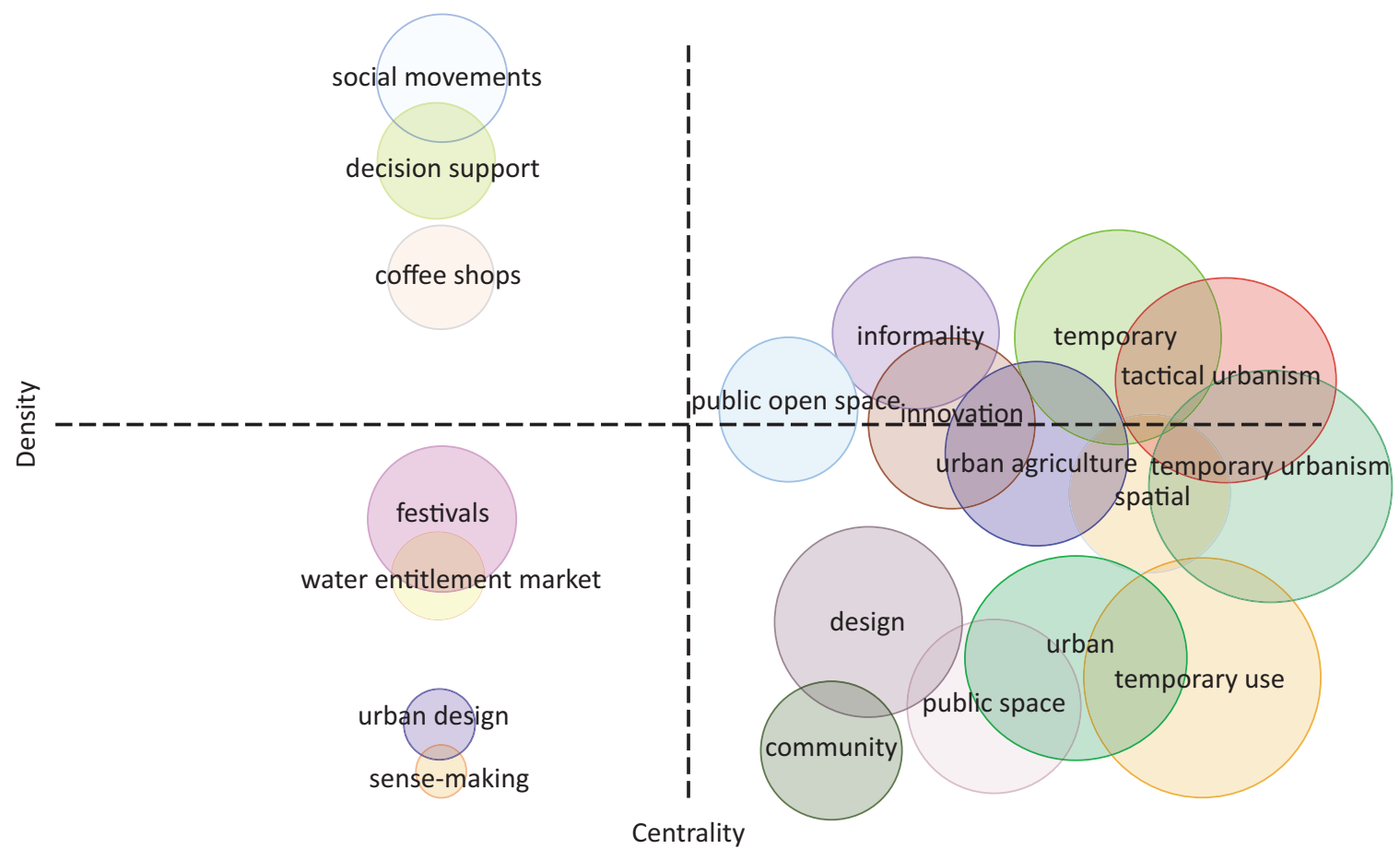

Figure 7. Thematic map of the 500 most common co-occurring keyword. Notes: Clustering and sizes are in relation the proportion of most common co-occurring words. Location determined by the Callon measure of density and centrality. 
to 'utopia,' 'heterotopia,' 'spatial production,' 'planning theory' or 'intersectional feminism' do no occur often with TU. In contrast, they populate the clusters for alternative signifieds for TU; this supports transfunctionalization of TU through more recent and emerging signifieds. This also reveals new constellations of signifieds, referents and signifying authors, which extend the theorization of TU.

We need not stop here, however, as we can also relate the transfunctionalization of TU to specific and influential publications. Recall that the authors of the publications are signifiers in the Semiotic Triangle who shape the articulation and symbolisms of TU in relation to select referents. The historical citation network in Figure 8 visualizes how scholars draw on preceding contributions to cite earlier concepts and support new ideas (full list is included in the Supplementary File under SM.3 Historical Direct Citation Network of Most Cited Publications). Socio-semiotically speaking and confirmed through content analyses, these authors act as signifiers and link to the signifieds mapped in Figure 7 (i.e., TU, 'Temporary Urbanism,' 'Tactical Urbanism'). More recent contributions draw on the earlier concept of TU to propel new signifieds. At the same time, these also contribute to the reiterative and layered transfunctionalization of TU. These are patterned in different streams of citations with varying historical and topical legacies.

The stream with the longest legacy dates back to Groth and Corijn's contribution from 2005. Their publication centrally discusses TU through ranges of activities in the context of socioeconomic changes by means of multiple case studies. Further, it characterizes TU as facilitating shifts in governance and land policy; while new meanings for the production of space are discussed, 'Temporary Urbanism' and 'Tactical Urbanism' as signifieds make no appearance (Groth \& Corijn, 2005).
A second and denser stream of citations draw on multiple works. These discuss TU while also introducing 'Temporary Urbanism' and 'Tactical Urbanism' as alternative signifieds (Andres, 2013; Harris, 2015; Honeck, 2017; Madanipour, 2018; Nemeth \& Langhorst, 2014; Patti \& Polyak, 2015; Tardiveau \& Mallo, 2014; Vallance et al., 2017). In addition, there is a divergence in the methods of investigating TU in these later works. This is evident in the range of case studies (they vary from none to 11 -the majority feature singular, in-depth case studies), integration of theoretical and analytical frameworks, inclusion of policy and discourse analyses, proposition or prototyping for new designs and even encouragement for pedagogical activism. This strongly suggests that TU is transfunctionalizing methodologically as well. TU is no longer framed solely as a pragmatic signified, but instead, understood through a plurality of meanings, studied in a variety of manners, and entangled in signification processes that draw from diverse communities and authors in scholarship. A Temporary Turn is reflected in scholarship as it is in practice, but more importantly, it is refracted through multiple socio-semiotic channels of urban scholarship.

\section{Discussion}

The socio-semiotic framework and bibliometric analyses that I present here delineate the early degrees of a Temporary Turn in urban planning research that transfunctionalizes TU. This shows how urban scholars articulate multiple symbols alongside TU, such as 'Temporary Urbanism' and 'Tactical Urbanism', fuelling what some might view as a boosterist, politics of signs (Gottdiener, 1986). The epistemic culmination of this capitalizes on and entrenches "place-bundles" of meaning through spatial, social and ideological processes (Zhang,

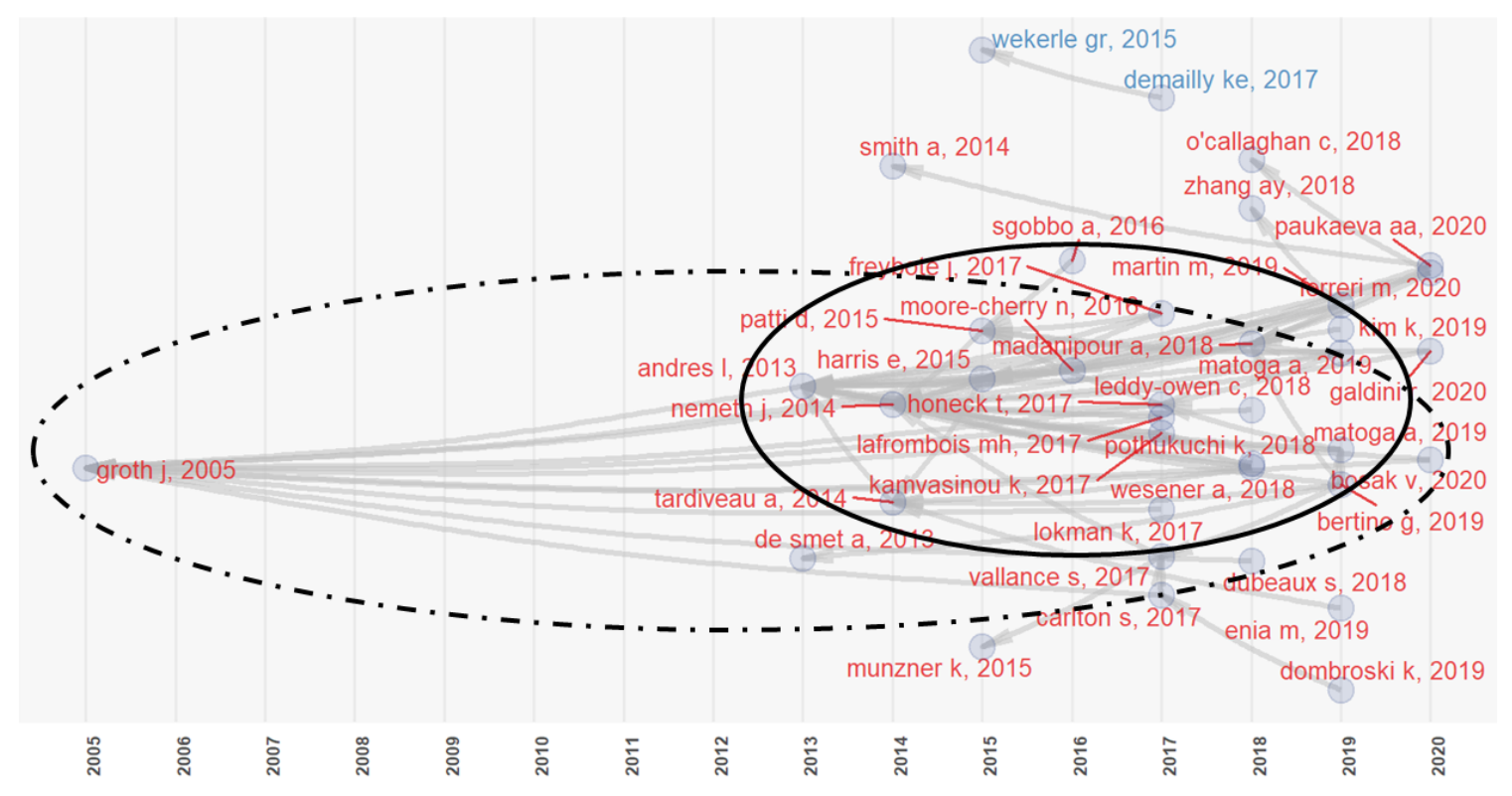

Figure 8. Historical direct citation network of most cited publications. 
2018, p. 92). These are "contentious and contingent...on the ability of special interests to control the symbolic interpretations of processual outcomes in everyday life" (Gottdiener, 1986, p. 207). Urban scholars prioritize certain themes and represent these through their design of the Semiotic Triangle and advancement of TU-relevant signifieds. Depending on the narratives or inherited ideologies, patterns in the selection of signified and referents can be uncovered. These punctuate historical and scientific lines of inquiry, which we can trace through bibliometric methods. A socio-semiotic lens reveals that TU is polysemic; it links and qualifies space, experience, and ideology through many signification processes. These also emphasize Ledrut's claim that indirectly, "a city can never be more or less significant, it can only signify differently" (1986b, p. 115). Scholars, along with planners and other participants in signification processes, amplify and augment its meanings. In doing so uncritically, they risk perpetuating similar narratives and missing out on other symbolic realities or confounding TU discourse with diverging symbols.

With this knowledge, future work should continue to attend to TU and its symbolism, as is already being carried forth by those who highlight weaknesses in our understanding. Theoretically, this invites scholars to craft narratives with greater consciousness on temporary interventions by looking for new avenues to position and produce meaning in space and discourse (LaFrombois, 2017). This also demands that urban scholars studying TU look outwardly to find, scrutinize and integrate meaning through alternative lenses. Whether these lenses are angled, for example, through intersectionality to spotlight referents still shadowed by our eagerness to focus on exceptional practice (LaFrombois, 2017; Martin et al., 2020) or culturally to consider romanticized policies and antipathetic reactions (Bosák, Slach, Nováček, \& Krtička, 2019; Honeck, 2018; Liu, 2017), there is still much work to do on TU. We have yet to fully understand more common forms and symbols of TU (Martin, Deas, \& Hincks, 2019) or explore the intersection of meanings, as is the case with 'T/T Urbanism' that represents a "twofold concept" (Stevens \& Dovey, 2018, p. 324). Indeed our capacity to "capture," "uncover" and "control" the symbols we communicate (Möystad, 2018, p. 48) about TU is still green. Most likely, this means that TU requires further study. There is place for this continued study in our journals, within our classrooms and even more so on our streets as recent challenges with the pandemic continue to heighten the immediate readiness for TU (Herman \& Rodgers, 2020).

Considering the recent normalization of TU through pandemic-oriented policies and Covid-19 circumstances (Herman \& Rodgers, 2020), citizens, practitioners and policy makers should also be made aware of the semantic challenges and socio-semiotic confusion involved with competing TU symbols. Certain social groups will prefer a particular TU signified over another. How these preferences finally present are often informed by the policy and research that urban scholars and planners perpetuate. In this light, the continuation of a critical and conscious treatment of TU is helpful in both theory and in practice. A more sensitive stipulation and re-working of how we communicate or manage communication about TU through collaborative transfer networks (Galdini, 2020) or policy publications (Patti \& Polyak, 2015) could also be starting points for future learning and application. Since these are informed by scholarship, they offer comparatively direct opportunities for scholars to exercise their insights into policy and practice.

\section{Conclusions}

Here, I presented a research about research explication of how scholars communicate the TU discourse through a socio-semiotic framework. This contribution makes use of the Semiotic Triangle and its mechanisms (referent, signifier, and signified) to explain the transfunctionalization of TU signifieds that are represented in scholarly literature. Bibliometric methods support these analytical findings. These firstly, delineate how TU and new symbols embodied by keywords such as 'Temporary Urbanism' and 'Tactical Urbanism' are traced in keyword growth, as well as thematic and historical citation developments. Secondly, these also explain theoretically how urban scholarship is unfurling a Temporary Turn by representing and producing meaning for temporary practices through keyword symbols. We can discern these through different constellations of referent, signifier and signified. These advance multiple and dynamic signification processes that transfunctionalize TU as symbolic myths. Many of which repeat neoliberal undertones sourced from the functional signs we observe in practice. By illuminating the manners in which we communicate TU in scholarship and reproduce qualities from practice, I encourage urban scholars to ponder how we collectively produce space and symbols while engaging in an emerging Temporary Turn. The insights here can impact how we communicate about TU in scholarship, but also shine light on opportunities through semiotic processes to consciously and meaningfully advance TU. We can continue to engender specific socioeconomic agendas in scholarly discourse while confusing with symbolic variations. We also have the choice to more carefully attend to how we frame, abstract, and refract TU. Whether this is through greater criticality, inclusivity or objectivitythe degree to which we control and communicate TU or a Temporary Turn is our design.

\section{Acknowledgments}

The author would like to thank Meg Holden for questioning the 'temporary' in TU. Gratitude also goes to Martin Eckert for sharing enthusiasm for the $\mathrm{R}$ language and environment. Ben Davy deserves thanks for the semiotic signal. Lasse Gerrits, Karsten Zimmermann, Christian 
Lamker, Rebecca Gunderson and Miriam Matejova were invaluable in the process of finding and formulating words. Matthias Wedewardt and Elisa Chang also helped with the final polish. Finally, this article would not be in the shape that it is, nor published without the editors and anonymous referees who provided helpful feedback.

\section{Conflict of Interests}

The author declares no conflict of interests.

\section{Supplementary Material}

Supplementary material for this article is available online in the format provided by the author (unedited).

\section{References}

Andres, L. (2013). Differential spaces, power hierarchy and collaborative planning: A critique of the role of temporary uses in shaping and making places. Urban Studies, 50(4), 759-775.

Andres, L., \& Golubchikov, O. (2016). The limits to artistled regeneration: Creative brownfields in the cities of high culture. International Journal of Urban and Regional Research, 40(4), 757-775.

Archambault, É., \& Gagné, É. V. (2004). The use of bibliometrics in the social sciences and humanities. Montreal: Science-Metrix.

Aria, M., \& Cuccurullo, C. (2017). Bibliometrix: An R-tool for comprehensive science mapping analysis. Journal of Informetrics, 11(4), 959-975.

Aria, M., Misuraca, M., \& Spano, M. (2020). Mapping the evolution of social research and data science on 30 years of social indicators research. Social Indicators Research, 149(3), 803-831.

Barthes, R. (1986). Semiology and the urban. In M. Gottdiener \& A. P. Lagopoulos (Eds.), The city and the sign: An introduction to urban semiotics (pp. 87-98). New York, NY: Columbia University Press.

Bishop, P., \& Williams, L. (Eds.). (2012). The temporary city. London and New York, NY: Routledge.

Bosák, V., Slach, O., Nováček, A., \& Krtička, L. (2019). Temporary use and brownfield regeneration in postsocialist context: From bottom-up governance to artists exploitation. European Planning Studies, 3(4), 1-23.

Bragaglia, F., \& Caruso, N. (2020). Temporary uses: A new form of inclusive urban regeneration or a tool for neoliberal policy? Urban Research \& Practice, $O(0)$, 1-21.

Centner, R. (2012). Microcitizenships: Fractious forms of urban belonging after argentine neoliberalism. International Journal of Urban and Regional Research, 36(2), 336-362.

Certoma, C., Corsini, F., \& Rizzi, F. (2015). Crowdsourcing urban sustainability: Data, people and technologies in participatory governance. Futures, 74, 93-106.
Chang, R. A. (2018). Temporary use and collective action: How urban planning practices contribute to adaptive capacity building for economic resilience. PlaNext: Next Generation Planning, 7, 82-99.

Colomb, C. (2012). Pushing the urban frontier: temporary uses of space, city marketing, and the creative city discourse in 2000s Berlin. Journal of Urban Affairs, 34(2), 131-152.

Comunian, R. (2017). Temporary clusters and communities of practice in the creative economy: Festivals as temporary knowledge networks. Space and Culture, 20(3), 329-343.

Copley, N., Bowring, J., \& Abbott, M. (2015). Thinking ahead: Design-directed research in a city which experienced fifty years of sea level change overnight. Journal of Landscape Architecture, 10(2), 70-81.

Davis, J. (2008). Re-imagining Bishopsgate goodsyard. $A R Q$-Architectural Research Quarterly, 12(1), 13-25.

De Bruijn, E., \& Gerrits, L. (2018). Epistemic communities in urban self-organization. Journal of Planning Literature, 33(3), 310-328.

Del Signore, M. (2017). Pneusense transcoding social ecologies. In A. Fioravanti, S. Cursi, S. Elahmar, S. Gargaro, G. Loffreda, G. Novembri, \& A. Trento (Eds.), ECAADE 2017: Sharing of computable knowledge! (Vol. 2, pp. 537-544). Brussels: ECAADE-Education \& Research Computer Aided Architectural Design Europe.

Demailly, K.-E., \& Darly, S. (2017). Urban agriculture on the move in Paris: The routes of temporary gardening in the neoliberal city. ACME: An International E-Journal for Critical Geographies, 16(2), 332-361.

Dinzey-Flores, Z. Z. (2007). Temporary housing, permanent communities: Public housing policy and design in Puerto Rico. Journal of Urban History, 33(3), 467-492.

Dombroski, K., Diprose, G., \& Boles, I. (2019). Can the commons be temporary? The role of transitional commoning in post-quake Christchurch. Local Environment, 24(4), 313-328.

Dubeaux, S., \& Cunningham Sabot, E. (2018). Maximizing the potential of vacant spaces within shrinking cities, a German approach. Cities, 75, 6-11.

Eco, U. (1986). Function and sign: Semiotics of architecture. In M. Gottdiener \& A. P. Lagopoulos (Eds.), The city and the sign: An introduction to urban semiotics (pp. 55-86). New York, NY: Columbia University Press.

Ferreri, M. (2019). Learning from temporary use and the making of on-demand communities in London's Olympic "fringes." Urban Geography, 41(3), 1-19.

Fu, Y., \& Zhang, X. (2017). Trajectory of urban sustainability concepts: A 35 -year bibliometric analysis. Cities, 60, 113-123.

Galdini, R. (2020). Temporary uses in contemporary spaces: A European project in Rome. Cities, 96, 1-8.

Gillespie, T., Hardy, K., \& Watt, P. (2018). Austerity urbanism and Olympic counter-legacies: Gendering, 
defending and expanding the urban commons in East London. Environment and Planning D: Society \& Space, 36(5), 812-830.

Gottdiener, M. (1984). Urban semiotics. In J. S. Pipkin, M. La Gory, \& J. R. Blau (Eds.), Remaking the city: Social science perspectives on urban design (pp. 101-114). New York, NY: State University of New York Press.

Gottdiener, M. (1985). Hegemony and mass culture: A semiotic approach. American Journal of Sociology, 90(5), 979-1001.

Gottdiener, M. (1986). Culture, ideology, and the sign of the city. In M. Gottdiener \& A. P. Lagopoulos (Eds.), The city and the sign: An introduction to urban semiotics (pp. 202-218). New York, NY: Columbia University Press.

Gottdiener, M. (2011). Socio-semiotics and the new mega spaces of tourism: Some comments on Las Vegas and Dubai. Semiotica, 2011(183), 121-128.

Gottdiener, M., \& Lagopoulos, A. P. (Eds.). (1986). The city and the sign: An introduction to urban semiotics. New York, NY: Columbia University Press.

Groth, J., \& Corijn, E. (2005). Reclaiming urbanity: Indeterminate spaces, informal actors and urban agenda setting. Urban Studies, 42(3), 503-526.

Harris, E. (2015). Navigating pop-up geographies: Urban space-times of flexibility, interstitiality and immersion. Geography Compass, 9(11), 592-603.

Havemann, A., \& Schild, M. (2007). 'You can use my tights' or: The phenomenon of temporary solutions. Landscape Research, 32(1), 45-55.

Herman, K., \& Rodgers, M. (2020). From tactical urbanism action to institutionalised urban planning and educational tool: The evolution of park(ing) day. Land, 9(7). https://doi.org/10.3390/land9070217

Hervas-Oliver, J.-L., Gonzalez, G., Caja, P., \& SempereRipoll, F. (2015). Clusters and industrial districts: Where is the literature going? Identifying emerging sub-fields of research. European Planning Studies, 23(9), 1827-1872.

Honeck, T. (2017). From squatters to creatives: An innovation perspective on temporary use in planning. Planning Theory \& Practice, 18(2), 268-287.

Honeck, T. (2018). A touch of post-truth: The roles of narratives in urban policy mobilities. Geographica Helvetica, 73(2), 133-145.

Iveson, K. (2013). Cities within the city: Do-it-yourself urbanism and the right to the city. International Journal of Urban and Regional Research, 37(3), 941-956.

Kassens-Noor, E. (2016). From ephemeral planning to permanent urbanism: An urban planning theory of mega-events. Urban Planning, 1(1), 41-54.

Kim, K. (2019). Rethinking temporary use coordinators for the regeneration of underused urban spaces in Seoul. Journal of Regional and City Planning, 30(1). http://dx.doi.org/10.5614\%2Fjpwk.2019.30.1.1

Kirby, A. (2012). Current research on cities and its contribution to urban studies. Cities, 29, S3-S8.
Krampen, M. (1979). Meaning in the urban environment. London: Pion Limited.

LaFrombois, M. H. (2017). Blind spots and pop-up spots: A feminist exploration into the discourses of do-it-yourself (DIY) urbanism. Urban Studies, 54(2), 421-436.

Ledrut, R. (1986a). The images of the city. In M. Gottdiener \& A. P. Lagopoulos (Eds.), The city and the sign: An introduction to urban semiotics (pp. 219-240). New York, NY: Columbia University Press.

Ledrut, R. (1986b). Speech and the silence of the city. In M. Gottdiener \& A. P. Lagopoulos (Eds.), The city and the sign: An introduction to urban semiotics (pp. 114-155). New York, NY: Columbia University Press.

Lefebvre, H. (1996). Writings on cities (E. Kofman \& E. Lebas, Trans.). Oxford: Blackwell.

Li, Y. (2017). A semiotic theory of institutionalization. Academy of Management Review, 42(3), 520-547.

Liu, X. (2017). "Contested policy mobility": The creative transformation and temporary use of brownfields in Redtory, Guangzhou. Urban Geography, 38(6), 1-19.

Madanipour, A. (2018). Temporary use of space: Urban processes between flexibility, opportunity and precarity. Urban Studies, 55(5), 1093-1110.

Martin, M., Deas, I., \& Hincks, S. (2019). The role of temporary use in urban regeneration: Ordinary and extraordinary approaches in Bristol and Liverpool. Planning Practice \& Research, 34(5), 537-557.

Martin, M., Hincks, S., \& Deas, I. (2020). Temporary use in England's core cities: Looking beyond the exceptional. Urban Studies, 57(16), 3381-3401.

Martini, L., \& Ramaccini, G. (2016). Spoleto paint of view: From the point to the pixel. In L. Corniello (Ed.), World heritage and degradation: Smart design, planning and technologies (pp. 150-156). Naples: Scuola Pitagora Editrice.

Matoga, A. (2019a). Governance of temporary use. Proceedings of the Institution of Civil Engineers: Urban Design and Planning, 172(4), 159-168.

Matoga, A. (2019b). How media shape the perception of temporary uses. DisP: The Planning Review, 55(1), 85-96.

McGlone, N. (2016). Pop-up kids: Exploring children's experience of temporary public space. Australian Planner, 53(2), 1-10.

Meerow, S., \& Newell, J. P. (2015). Resilience and complexity: A Bibliometric review and prospects for industrial ecology. Journal of Industrial Ecology, 19(2), 1-16.

Meerow, S., Newell, J. P., \& Stults, M. (2016). Defining urban resilience: A review. Landscape and Urban Planning, 147, 38-49.

Möystad, O. (2018). Cognition and the built environment. New York, NY: Routledge.

Muniandy, P. (2015). Informality and the politics of temporariness: Ethnic migrant economies in Little Bangladesh and Little Burma in Kuala Lumpur, Malaysia. International Sociology, 30(6), 561-578. 
Nemeth, J., \& Langhorst, J. (2014). Rethinking urban transformation: Temporary uses for vacant land. Cities, 40, 143-150.

O'Callaghan, C., Di Feliciantonio, C., \& Byrne, M. (2018). Governing urban vacancy in post-crash Dublin: Contested property and alternative social projects. Urban Geography, 39(6), 1-24.

Ogden, C. K., \& Richards, I. A. (1966). The meaning of meaning: A study of the influence of language upon thought and of the science of symbolism (10th ed.). Mansfield Centre: Martino Publishing.

Oswalt, P., Overmeyer, K., \& Misselwitz, P. (Eds.). (2013). Urban catalyst: The power of temporary use. Berlin: Dom Pub.

Overdiek, A. (2018). Opportunities for slow fashion retail in temporary stores. Journal of Fashion Marketing and Management, 22(1), 67-81.

Patti, D., \& Polyak, L. (2015). From practice to policy: Frameworks for temporary use. Urban Research \& Practice, 8(1), 122-134.

Prawata, A. (2015). Creative user generated urbanism. Procedia: Social and Behavioral Sciences, 184, 232-239.

Rall, E. L., \& Haase, D. (2011). Creative intervention in a dynamic city: A sustainability assessment of an interim use strategy for brownfields in Leipzig, Germany. Landscape and Urban Planning, 100(3), 189-201.

Remm, T. (2016). Textualities of the city: From the legibility of urban space towards social and natural others in planning. Sign Systems Studies, 44(1/2). https://doi.org/10.12697/SSS.2016.44.1-2.03

Rian, I. M., Chang, D., Park, J.-H., \& Ahn, H. U. (2008). Pop-up technique of origamic architecture for postdisaster emergency shelters. Open House International, 33(1), 22-36.

Rota, F. S., \& Salone, C. (2014). Place-making processes in unconventional cultural practices: The case of Turin's contemporary art festival Paratissima. Cities, 40, 90-98.

Schrooten, P., Coopman, A., \& Kindt, V. (2007). Appli- cation of a combined risk-based, remedial and redevelopment methodology on a former cokes plant. In A. Kungolos, C. A. Brebbia, \& E. Beriatos (Eds.), WIT transactions on ecology and the environment, sustainable development and planning III (Vols. 1-2, pp. 105-112). Ashurst: WIT Press. https://doi.org/ 10.2495/SDP070101

Stevens, Q. (2018). Temporary uses of urban spaces: How are they understood as 'creative'? International Journal of Architectural Research: ArchNet-IJAR, 12(3), 90-107.

Stevens, Q., \& Dovey, K. (2018). Pop-ups and public interests: Agile public space in the neoliberal city. In M. Arefi \& C. Kickert (Eds.), The Palgrave handbook of bottom-up urbanism (Vol. 76, pp. 323-337). Cham: Palgrave Macmillan.

Stillwagon, R., \& Ghaziani, A. (2019). Queer pop-ups: A cultural innovation in urban life. City \& Community, 18(3), 874-895.

Szaton, K. M. (2018). The temporary use as a strategy for transforming the space of contemporary cities: Space transformations supported by the purposeful application of temporary use, based on a case study. Miscellanea Geographica, 22(4), 231-236.

Talen, E. (2015). Do-it-yourself urbanism. Journal of Planning History, 14(2), 135-148.

Tardiveau, A., \& Mallo, D. (2014). Unpacking and challenging habitus: An approach to temporary urbanism as a socially engaged practice. Journal of Urban Design, 19(4), 456-472.

Vallance, S., Dupuis, A., Thorns, D., \& Edwards, S. (2017). Temporary use and the onto-politics of 'public' space. Cities, 70, 83-90.

Wesener, A. (2018). How to contribute to urbanity when the city centre is gone: A design-directed exploration of temporary public open space and related notions of urbanity in a post-disaster urban environment. Urban Design International, 23(3), 165-181.

Zhang, A. Y. (2018). Thinking temporally when thinking relationally: Temporality in relational place-making. Geoforum, 90, 91-99.

\section{About the Author}

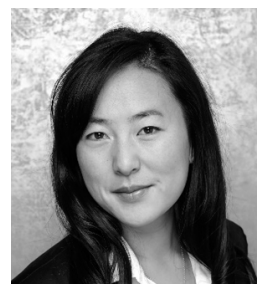

Robin A. Chang is a PhD Researcher and Lecturer based at the School of Spatial Planning from the Technical University of Dortmund. Prior to joining the Department of European Planning Cultures at the School of Spatial Planning in 2015, she practiced planning in her home country of Canada where she was trained as a Natural Resource Planner. Her current research concentrates on temporary uses and adaptive planning approaches in complex urban systems. 